\title{
A TEORIA DAS RESTRIÇÕES EM UM PROCESSO DE FABRICAÇÃO DA INDÚSTRIA NA CONSTRUÇÃO CIVIL: UM ESTUDO DE CASO
}

\author{
The theory of constrains in a manufecture process \\ of civil construction: A case study
}

Envio 28.09.09 / Aceite 12.12.09

\author{
Ivana Helena de La-Rocque Soares ${ }^{1}$ \\ Daniel Reis Armond-de-Melo ${ }^{2}$ \\ Cláudio Bezerra Leopoldino ${ }^{3}$ \\ Júlio Cesar Andrade de Abreu ${ }^{4}$ \\ Flávio Machado Moita ${ }^{5}$
}

\begin{abstract}
Resumo
Este artigo descreve a elaboração de uma proposta de mudança para melhoria do processo produtivo, realizada com base nos pressupostos da Teoria das Restrições. Segundo esta teoria, uma restrição é qualquer elemento que afete negativamente um sistema, dificultando a obtenção de um melhor desempenho em relação a sua meta, mas que também pode ser explorado de forma que se obtenha uma melhoria de seus resultados. O trabalho foi realizado em uma indústria de lajes préfabricadas localizada na cidade de Manaus (AM), e se restringiu à fabricação de vigotas treliçadas, quando se constatou gargalo significativo na linha de produção observada e gasto indesejável com horas extras. Para o aprimoramento do processo produtivo, foram coletados e analisados dados e aplicados os fundamentos da Teoria das Restrições, com a quantificação dos efeitos positivos a serem obtidos com a efetivação das medidas propostas. O texto discorre ainda sobre a Teoria das Restrições em si e aponta

\footnotetext{
${ }^{1}$ Aluna da Especialização em Engenheiro de Planejamento da Universidade Federal do Amazonas (UFAM). E-mail: ivanalarocque@hotmail.com

${ }^{2}$ Professor Assistente I do Instituto de Ciências Exatas e Tecnologia da UFAM. E-mail:armond@ufam.edu.br

${ }^{3}$ Doutorando em Administração da Universidade Federal da Bahia. E-mail: claudiob_br @yahoo.com.br

${ }^{4}$ Administrador, mestre em Administração (UFBA), doutorando em Administração (UFBA). Professor Assistente da Universidade Federal Fluminense, Pólo Universitário de Volta Redonda. E-mail: jandrade0@gmail.com

${ }^{5}$ Professor Assistente I do Departamento de Administração da UFAM. E-mail: flaviomoita@ufam.edu.br; flaviomoita@ uol.com.br.
} 
de que forma a sua aplicação pode resultar em ganhos mensuráveis nos processos da construção civil e em outros campos.

Palavras-chave: Teoria das Restrições; Gestão de Produção; Construção Civil.

\section{Abstract}

This article describes the change in a manufacturing process based on the Theory of Constraints (TOC). According to the TOC, a constraint is any element that reduces the performance of a system. However, these constraints, if properly identified and broken, provide the fastest route to significant improvement for the system and can provide the basis for production improvement. The research was developed in a civil construction plant in the city of Manaus, Brazil, where it was detected a production bottleneck. The TOC fundamentals were applied to the manufacturing process and positive results were obtained and quantified.

Keywords: Theory of Constrains; Manufactory Process; Civil Construction.

\section{Introdução}

A partir da publicação do livro A Meta, na década de 1980, a Teoria das Restrições se tornou uma referência no que tange a processos de melhoria nas organizações, guiando a busca por soluções aos problemas enfrentados. No campo da gestão da produção, sua aplicação vem mudando a forma de agir e pensar dos profissionais (MARTINS, 2002).

A Teoria das Restrições, conhecida como TOC (Theory of Constraints), apresenta soluções para os problemas enfrentados em sistemas tradicionais da gestão de produção e quebrar paradigmas que regem as organizações, mudando a forma de agir e pensar das pessoas. Segundo essa teoria, gargalo é um estreitamento na saída de processo produtivo que impede o próprio processo de ser mais eficiente, pois tudo que vem depois, ou mesmo antes deste, fica dependente da restrição imposta pelo gargalo. Um gargalo pode estar antes, no meio ou na saída de um processo ou, até mesmo, ser um fator externo, como o mercado. Em um processo podem existir mais de uma restrição.

No Brasil e no mundo, a Teoria das Restrições tem oferecido contribuições em diversos ramos empresariais. Internacionalmente Noreen, Smith e Mackey (1996) citam aplicações nas organizações em diversos segmentos, como o setor de saúde, ferramentas, tecidos, malas de viagem, indústria de enlatados, gráficas, armários sob medida. Resende Júnior (2006) detalha uma aplicação na área de Sistemas Logísticos. Martins (2002) apresenta casos brasileiros de utilização da TOC nos campos de fabricação de autopeças, instituições de ensino superior, academia de ginástica e natação, setor bancário, entre outros. Aguiar et al. (2004) relatam a aplicação da TOC em indústria da construção civil (gesso acartonado).

Este artigo retrata a elaboração de proposta de melhoria no processo produtivo de uma indústria de pré-fabricados de lajes treliçadas, instalada na cidade de Manaus (AM), com base na Teoria das Restrições. O ambiente se revelou propício para a implantação de processos formais de melhoria, pois as atividades de produção são eminentemente artesanais e a demanda atual supera a capacidade fabril, evidenciando gargalos e inconsistências a serem sanados.

Os resultados das investigações realizadas foram quantificados e se encontram aqui detalhados, servindo de diagnóstico dos problemas e guias para a atuação nas áreas prioritárias 
identificadas. Como resultado, também foram propostas mudanças nos recursos humanos e na estrutura física da fábrica para serem implantadas na instalação atual e nas instalações futuras visando ao atendimento das demandas do mercado mesmo nos períodos de aumento, com redução dos custos com desperdícios e horas extras.

\section{Metodologia}

Vergara (2004) classifica as pesquisas quanto aos fins e quanto aos meios empregados. A pesquisa apresentada neste artigo classifica-se quanto aos fins como exploratória, descritiva e explicativa, pois tem como objetivo tornar o assunto inteligível, esclarecer os fatores que, de alguma forma, determinam e contribuem para ocorrência do fenômeno. Quanto aos meios, foi realizado um estudo de caso, com coleta de dados em ambiente de produção, incluindo o levantamento de documentos e imagens fotográficas, entrevistas não-estruturadas com gestores e trabalhadores. O estudo de caso é indicado neste tipo de pesquisa, segundo Procópio e Silva (2005) e Yin (2004), pois se trata de um método de investigação que se concentra sobre o estudo de um determinado contexto, analisando e descrevendo ao mesmo tempo o objeto ou situação pesquisada.

A análise de resultados teve o suporte de uma revisão bibliográfica em Teoria das Restrições, servindo como fundamento para a elaboração de propostas de melhorias das práticas de produção da indústria de vigotas treliçadas. Posteriormente foi feito um levantamento do processo produtivo da fábrica in loco. Os dados obtidos permitiram uma visão geral das etapas da produção, do leiaute físico das instalações e dos problemas vivenciados.

A esta etapa seguiu-se a análise do problema com base na Teoria das Restrições. Foram diagnosticados problemas e propostas soluções, com estimativa quantitativa do retorno econômico a ser obtido e sugestões de mudanças foram indicadas para retorno rápido e ganho de eficiência significativo no processo fabril.

\section{Pressupostos da Teoria das Restrições}

Segundo a TOC, em todo processo produtivo existe pelo menos uma restrição que limita sua eficiência. Considerando-se a empresa ou fábrica como um sistema, a teoria prescreve que se faça uma intervenção seletiva para um melhor desempenho, através dos principais gargalos (ou restrições) que impeçam o atingimento das metas propostas.

Resende Júnior (2006, p. 10) relaciona a aplicação da Teoria das Restrições de forma metodológica à visão da empresa como sistema aberto e a associa à necessidade de gestão de processos adaptativos. Cox III e Spencer (2002, p. 28) advertem que o gerenciamento de restrições:

\footnotetext{
é uma nova abordagem que planeja e controla a produção e venda de produtos e serviços. Esta abordagem reconhece o poderoso papel que a restrição (o recurso limitante) desempenha na determinação da saída do sistema de produção como um todo. Através do conhecimento e da compreensão dos aspectos envolvidos com o gerenciamento das restrições, os gerentes podem perceber melhorias imediatas no resultado de suas organizações e, através de uma abordagem focalizada de aprimoramento contínuo, podem planejar para suprir também as necessidades futuras.
}

Inicialmente sua difusão ocorreu no âmbito da administração da produção, no entanto, são conhecidas aplicações nas áreas de marketing e vendas, finanças e contabilidade, 
gerência de projetos, cadeias de suprimento e manufatura. A Figura 1 detalha os pressupostos e principais áreas de aplicação da Teoria das Restrições.

A TOC, proposta por Goldratt e Cox (2003), prescreve cinco passos para melhorar a utilização dos sistemas de produção por meio de intervenções sobre as restrições. Segundo os autores, consiste em examinar cinco etapas:

I - IDENTIFICAR a restrição do sistema;

II - EXPLORAR a restrição do sistema;

III - SUBORDINAR tudo o mais à decisão do item II;

IV- ELEVAR a restrição do sistema;

V - EVITAR A INÉRCIA. Se a restrição for quebrada, retornar à etapa I.

A TOC prescreve, ainda, que, em processos de produção, a sua programação seja definida com base na Lógica Tambor-Pulmão-Corda (TPC), descrita a seguir. Um tambor seria um item da cadeia que restringe a produção como um todo, determinando o ritmo do processo. Os tambores devem ser identificados para que se possam tratá-los como restrições do sistema.

O pulmão é um mecanismo que é agregado ao sistema de produção, para que o tambor mantenha-se sempre em atividade. Este mecanismo permite que as restrições causadas pelo tambor sejam menores, enquanto não são tomadas providências adicionais e o tambor deixe de ser uma restrição. Resende Júnior (2006, p. 46) afirma que os pulmões agregam recursos para o tambor, principalmente tempo e materiais.

Corda é um mecanismo de sincronização entre o pulmão e o tambor. Dessa forma, qualquer incidente envolvendo esses elementos será imediatamente tratado. Resende Júnior (2006, p. 46) afirma que as cordas efetuam a comunicação "entre o processo de restrição e o processo final que controla ou limita o material" a ser liberado para sustentar a restrição.

A aplicação da TOC através das cinco etapas se inicia quando são identificadas as restrições que existem no sistema, cuja programação será denominada de Tambor e, como próprio nome diz, é o que dita o ritmo da produção, e todo sistema tem pelo menos uma restrição que pode ser física, como uma máquina com baixa capacidade produtiva, ou não física, como as de política da empresa, comportamentais, culturais ou de mercado, conforme advertem Corrêa e Gianesi (1996, p. 155):

Num ambiente de Manufatura, há uma série de restrições a serem consideradas: restrições de mercado, restrições quanto ao fornecimento, restrições dadas pela política da empresa e restrições de capacidade do processo produtivo.

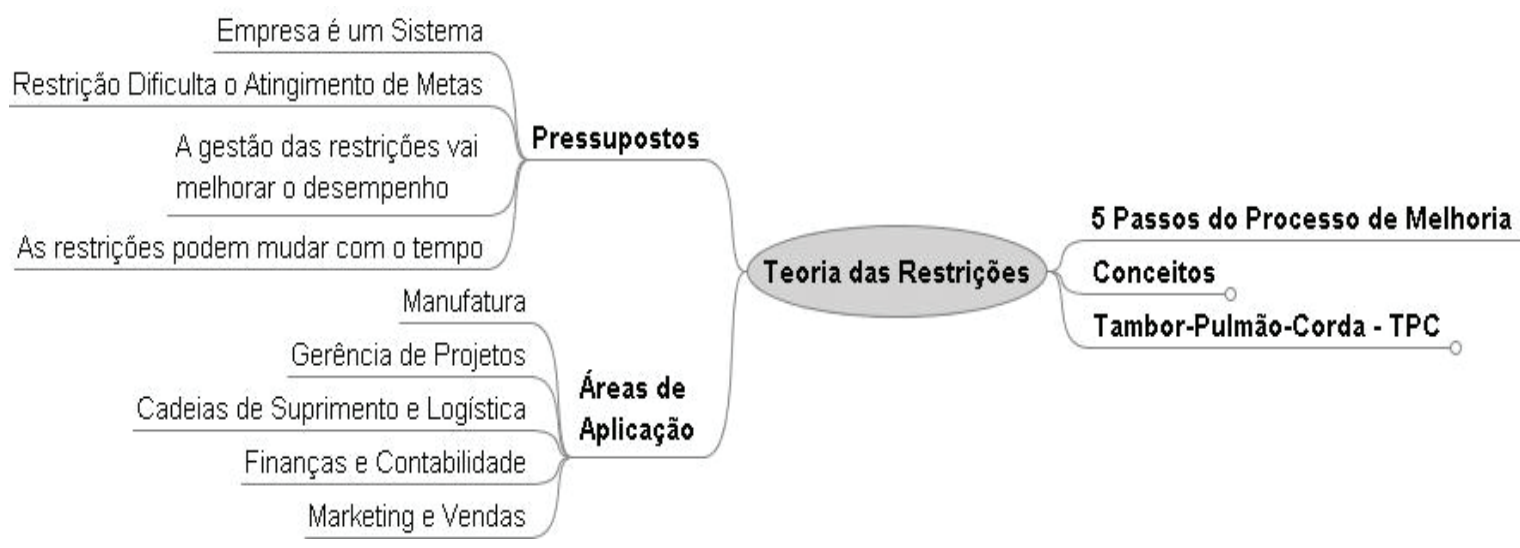

Fonte: Baseada em Correa e Gianesi (1996).

Figura 1 - Teoria das Restrições - Pressupostos e áreas de aplicação. 
Queiroz (2006) e Guerreiro (1999) afirmam que, para aumentar o desempenho do sistema, deve-se identificar o seu elo mais fraco. Goldratt e Cox (2003) apontam algumas formas de identificação da principal restrição. Uma delas é através de cálculos de carga de máquina impostos pela demanda versus capacidade de cada recurso. Outra forma, mais simples, é fazer um passeio pela fábrica, buscando verificar onde se encontra a maior fila de espera para processamento. Outra sugestão é conversar com os operários e perguntar que recurso normalmente atrasa as entregas. O segundo passo consiste em explorar (maximizar) o uso da restrição.

Segundo Corrêa e Gianesi (1996), explorar a restrição de um processo significa tirar o máximo de produção dela, ou seja, não desperdiçar tempo com atividades que não sejam convertidas em produção. Um exemplo de desperdício de tempo é a preparação de equipamento (setup). Queiroz (2006) afirma que a segunda etapa é onde se decide como explorar as restrições do sistema.

Souza (2006), seguindo a linha de Goldratt e Cox (2003), sugere que há vários modos de explorar o recurso com restrição de capacidade. Algumas sugestões do autor são: fazer uma programação detalhada; melhorar o mix de produtos; garantir que apenas produtos com qualidade assegurada passarão pelo gargalo; reduzir os tempos de preparação; manter rígido controle de manutenção corretiva e preventiva.

Outra forma de maximizar a sua utilização é assegurar que a produção deste recurso não pare por falta de material para processamento. Uma das estratégias utilizadas é manter estoque de segurança antes desses recursos gargalos. Esses estoques são conhecidos como pulmões e funcionam como um colchão que amortece as diferenças de produção entre as etapas dos processos. Também auxiliam no controle dos impactos decorrentes de imprevistos, devido a eventos aleatórios e flutuações estatísticas que venham interromper o sistema.

O terceiro passo faz a proposta de subordinar todos os recursos à restrição, ou seja, a batida do tambor, utilizando o mecanismo da corda ligando as operações de liberação de matéria-prima ao pulmão de forma que não prejudique a própria restrição e nem a obtenção do lucro máximo. Os recursos não restritivos não podem deixar faltar material para o gargalo; por outro lado, não devem trabalhar mais rápido que a restrição, pois estariam aumentando o nível de estoque da linha. Desta forma, o objetivo principal deve ser o de fazer com que as não restrições andem no mesmo passo das restrições (QUEIROZ, 2006). Nessa etapa, fica bem claro o que deve ser feito com os recursos não restrição, mas, se ainda assim a restrição estiver operando em sua capacidade máxima com todos os recursos subordinados a ela e ainda estiver com capacidade inferior à demanda, torna-se necessário elevar a restrição do sistema.

O quarto passo prega que a capacidade do gargalo deve ser aumentada com compra de novos equipamentos, contratação de mão de obra, desenvolvimento de processos ou matérias-primas alternativas. Neste ponto, todos os esforços já foram feitos para explorar ao máximo a restrição. Segundo Souza (2006), normalmente, uma restrição física é quebrada a partir de investimentos. Este é o grande diferencial entre explorar e elevar.

O último passo é avaliar se alguma restrição foi relaxada, isto é, se ela deixou de ser um gargalo para o sistema. Caso isso ocorra, deve-se voltar ao primeiro passo e reiniciar o processo.

De acordo com Goldratt e Cox (2003), é importante que, após estes cinco passos, se as capacidades produtivas foram alteradas e a restrição já foi sanada, o sistema todo deve ser revisto para que a própria inércia não tome conta do sistema e venha a se tornar restrição, garantindo, dessa forma, a melhoria no processo.

A Figura 2 apresenta um resumo dos conceitos da teoria das restrições e da lógica de Tambor-Pulmão-Corda. 


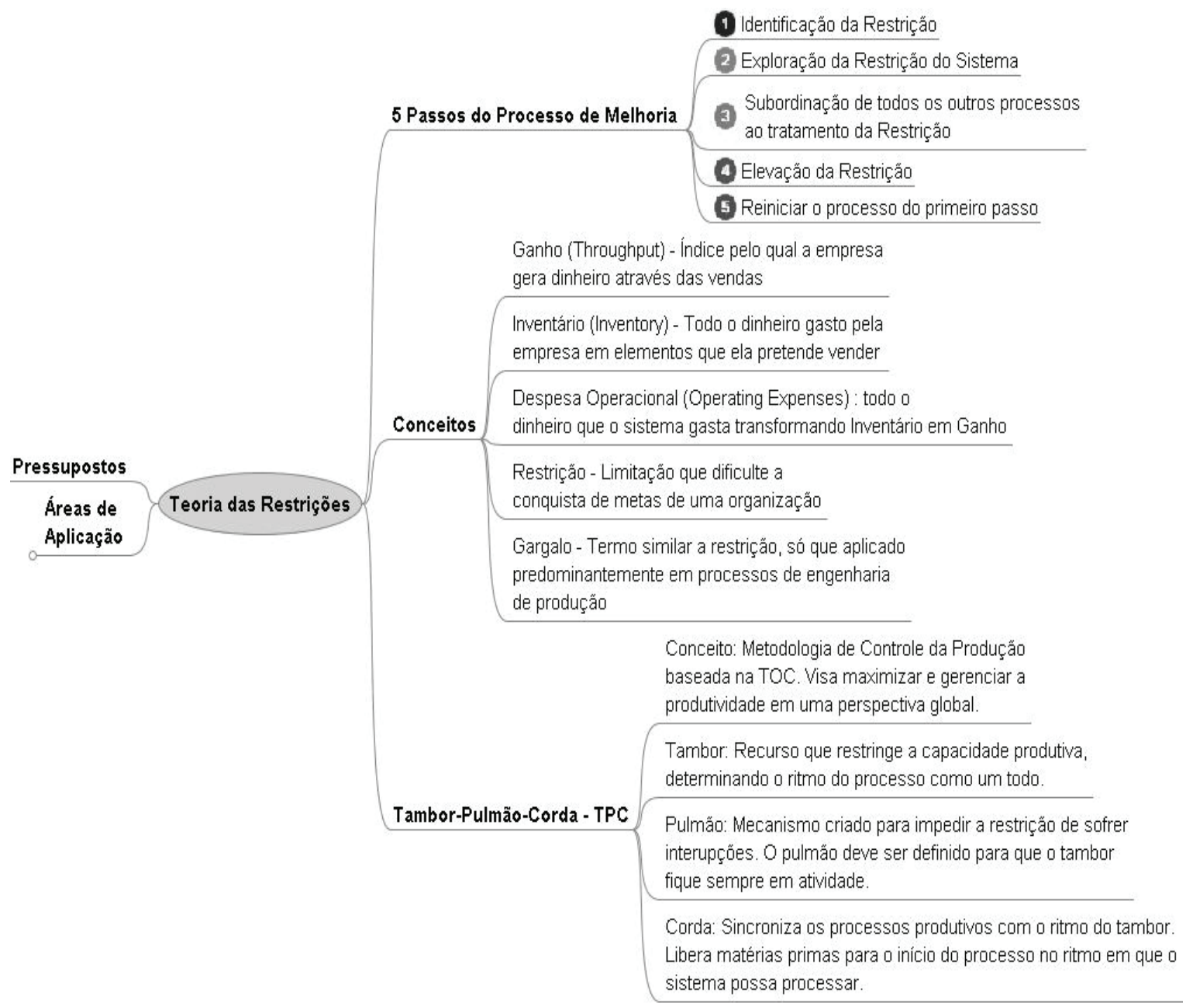

Fonte: Baseado em Goldratt e Cox (2003).

Figura 2 - Teoria das Restrições - Processo de Melhoria e Conceitos.

\section{Desenvolvimento do caso}

\subsection{A empresa}

Fundada na cidade de Manaus (AM), em maio de 2007, a fábrica aqui analisada atua no ramo da indústria da construção civil na fabricação de pré-fabricados de laje treliçada de concreto armado com enchimento em placas de poliestireno expandido (EPS) que, no Brasil, é vulgarmente conhecido como isopor.

Este tipo de laje é largamente empregado para uso residencial, comercial, industrial e outros, com a finalidade de uso para pisos, coberturas e paredes de contenção e tem capacidade para vencer vão livre de até 17 metros e suportar cargas até 5 ton $/ \mathrm{m} 2$. O que desperta o grande interesse por esse tipo de laje é o fato de acelerar a execução da obra, conforme afirmam Botelho e Marchetti (2002).

A fábrica atende a demanda de acordo com cada pedido, de forma personalizada e, por esse motivo, não há estoque de produto acabado, somente estoque de matéria-prima.

A empresa tem escritório de vendas para atender clientes no varejo e atacado e dispõe também de profissionais de vendas em atendimentos externo. Além do escritório, a empresa 
possui duas unidades fabris, sendo uma em galpão, onde toda a fabricação do produto é desenvolvida e o resultado expedido para a obra do cliente, e outra unidade no próprio canteiro de obras, que visa a atender somente aos clientes no atacado, como é o caso das construtoras.

O mercado para esse produto é fortemente sujeito à variação climática da região, ficando incipiente nos períodos de chuva. Nos demais períodos, a empresa atua sempre na sua capacidade limite. Em virtude do aumento da demanda por parte do mercado da construção civil na região de Manaus, a empresa analisada adquiriu nova área de ampliação para fábrica com o objetivo de dobrar sua capacidade produtiva até dezembro de 2008, no entanto, a busca por resultados mais imediatos levou ao questionamento do processo produtivo corrente.

\subsection{Processo produtivo antes da aplicação da TOC}

Produzida a partir de treliças de aço estrutural, a laje treliçada, principal produto da empresa, demanda, na sua produção, a mesma segurança prescrita para as lajes convencionais, que estão asseguradas pelas Normas Técnicas Brasileiras NBR 14859-1. São compostas por barras tracionadas (banzo inferior) e barras comprimidas (banzo superior), soldadas por meio de eletrofusão a outra barra em forma de diagonal (armadura de cisalhamento).

O material pré-fabricado das lajes é formado a partir da treliça de aço e de uma pequena placa de concreto armado de três centímetros de espessura e treze centímetros de largura, que envolve totalmente o banzo inferior da treliça e, após a concretagem, a peça recebe o nome de vigota treliçada. O concreto estrutural da vigota treliçada deve ter, no mínimo, uma resistência de compressão de $20 \mathrm{kgf} / \mathrm{cm} 2$, conforme exige a NBR.

A produção da vigota é executada em fôrmas metálicas, medindo três centímetros de altura e treze centímetros de largura dispostas em bancadas em forma de pistas e que podem variar em comprimento de acordo com a área do galpão onde está instalada a fábrica.

A empresa fabrica diversos tipos de lajes de acordo com a necessidade do cliente e a compra da matéria-prima é solicitada pela fábrica ao escritório para uma produção média mensal.

A fabricação inicia-se a partir do recebimento da planilha de produção, que é enviada pelo escritório de vendas à fábrica. Nela deve constar o nome do cliente, o tipo de laje, o comprimento de cada vigota (medidas no local da obra) e o aço adicional, que deve ser fornecido pelo projetista de estruturas.

O aço adicional é assim denominado porque será acrescentado no momento da produção e complementa o aço existente no banzo inferior da treliça com o objetivo de atender aos esforços solicitados no cálculo estrutural.

A planilha de produção segue para a área de corte e dobra de aço e treliça, os quais, depois de cortados, seguem para as fôrmas metálicas que deverão estar isentas de sujeira e totalmente cobertas por produto desmoldante para facilitar a desforma.

Em seguida, as fôrmas recebem uma camada de concreto de 1,5 cm, denominada de lastro, que serve para dar cobrimento à armadura de tração da treliça com a finalidade de protegê-la da corrosão de acordo com a NBR 6118. Após essa primeira camada, a treliça e os aços adicionais são colocados na fôrma e procede-se o restante da concretagem.

Depois de concretadas, as peças passam por um processo de cura do concreto e devem ser molhadas durante o período em que ficarem nas fôrmas, que deve ser de, no mínimo, vinte e quatro horas, para depois proceder a desforma do material. Caso sejam desformadas antes do prazo, ficarão sujeitas à diminuição da resistência ou mesmo perda total da peça. As peças são identificadas com tinta, de acordo com a dimensão, o tipo de laje e o nome do cliente. 
Para compor todo o material pré-fabricado, juntamente com as vigotas treliçadas, é fornecido EPS em placas com altura, conforme cada tipo de laje especificado no pedido. O EPS não tem finalidade estrutural e apenas serve como enchimento, complementando o material pré-fabricado.

O processo, desde a entrega da planilha de produção na fábrica até a entrega do material ao cliente, dura, idealmente, cinco dias úteis, e acontece conforme fluxo representado na Figura 3.

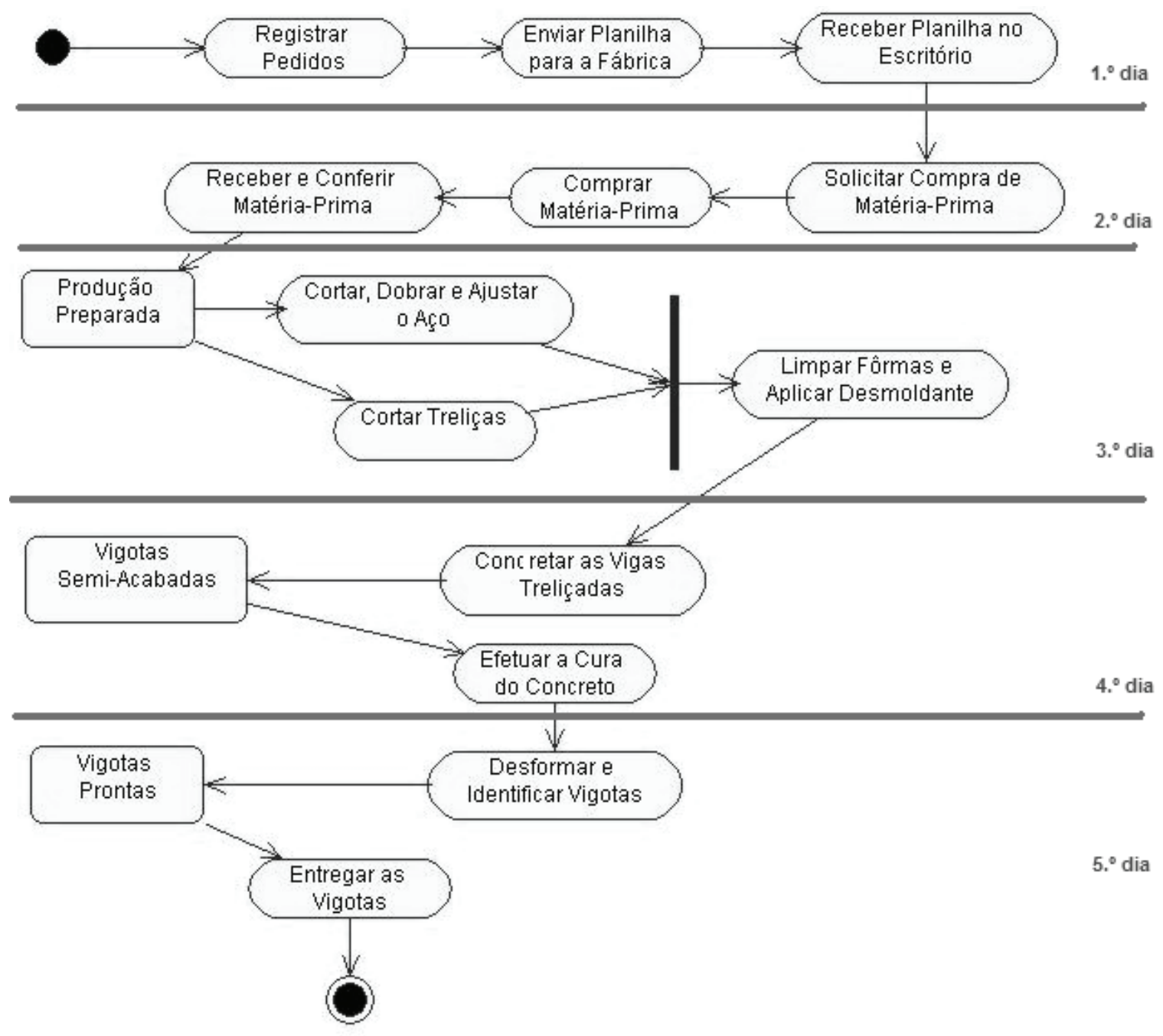

Fonte: Pesquisa de Campo (2008).

Figura 3 -- Fluxograma do processo produtivo.

\subsection{Aplicação da Teoria das Restrições}

O processo produtivo foi alterado de acordo com as prescrições da TOC, os cinco passos ou etapas. Cada uma dessas etapas será detalhada a seguir, conforme aplicadas ao caso em estudo. 


\subsubsection{Identificando a restrição}

Atualmente a capacidade produtiva da fábrica chega a consumir 100\% do tempo da mão de obra para um turno de trabalho. Quando é necessário atender os pedidos emergenciais, a empresa tem que operar nos finais de semana ou contratar mão de obra terceirizada.

A fábrica está instalada em uma área de $8 \mathrm{~m}$ de largura por $42 \mathrm{~m}$ de comprimento e tem um total de 900 m de pistas de fôrma para produção das lajes, sendo que a área restante do galpão serve para armazenar matéria-prima e maquinários como mostra o leiaute na Figura 4.

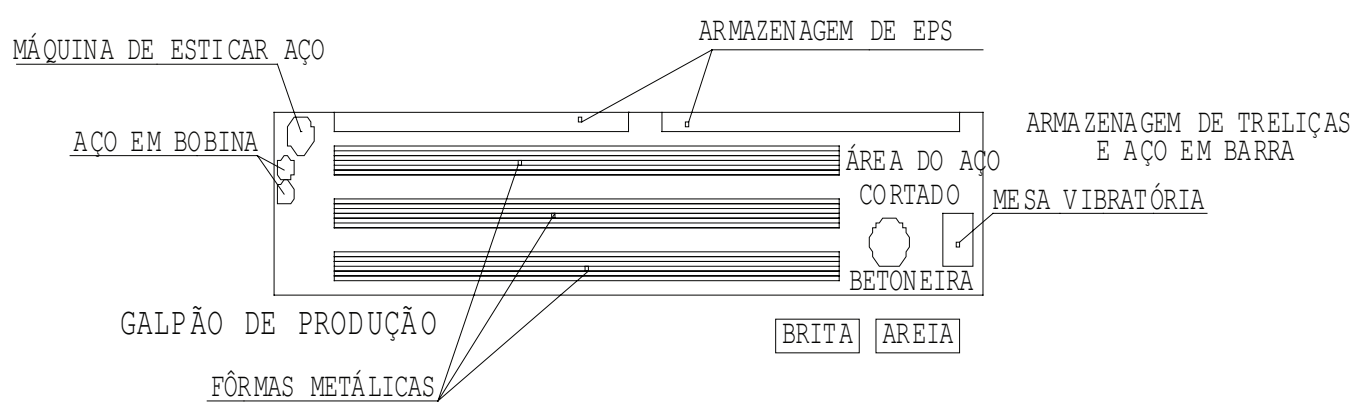

Fonte: Pesquisa de Campo (2008)

Figura 4 - Leiaute da fábrica.

A empresa conta com seis operários, distribuídos na produção da seguinte forma: um ferreiro, um betoneiro e quatro ajudantes. O ferreiro e o betoneiro são funcionários especializados. Os outros quatro operários, denominados de ajudantes, revezam-se nos processos de concretagem, limpeza das fôrmas, desforma e entrega do produto.

A partir da mensuração das capacidades de produção diárias de cada recurso, identificou-se que a atividade do ferreiro é uma restrição para o sistema como um todo, conforme se observa na Tabela 1. Esta avaliação ocorreu no mês de setembro de 2007.

Tabela 1 - Capacidade produtiva x demanda (diárias)

\begin{tabular}{|c|c|c|c|c|}
\hline Equipamentos & unidade & capacida de & demanda & demanda/capacidade \\
\hline Betoneira & $\mathrm{m} 3$ & 8 & 1,36 & $17 \%$ \\
\hline Máq. de esticar ferro & $\mathrm{kg}$ & 600 & 405 & $68 \%$ \\
\hline Máq. de cortar ferro & $\mathrm{kg}$ & 600 & 405 & $68 \%$ \\
\hline Mão de obra & & & & \\
\hline Betoneiro (operando máq.) & $\mathrm{h}$ & 9 & 9 & $100 \%$ \\
\hline Ferreiro (corte e dobra) & $\mathrm{kg}$ & 225 & 405 & $180 \%$ \\
\hline Ajudantes (concretagem) & $\mathrm{m}$ & 900 & 343 & $38 \%$ \\
\hline
\end{tabular}

Fonte: Pesquisa de Campo (2008).

Mesmo com aumento da demanda, a mão de obra permaneceu a mesma, e esta já vinha, nos meses anteriores, trabalhando na sua capacidade limite, pois a capacidade máxima produtiva da fábrica em peças de vigotas treliçadas é de $1.980 \mathrm{~m}$ por mês, podendo ser 
aumentada em até duas vezes essa capacidade se forem utilizadas as fôrmas reservas que ficam instaladas em local provisório e são removidas após o uso, conforme Figura 5.

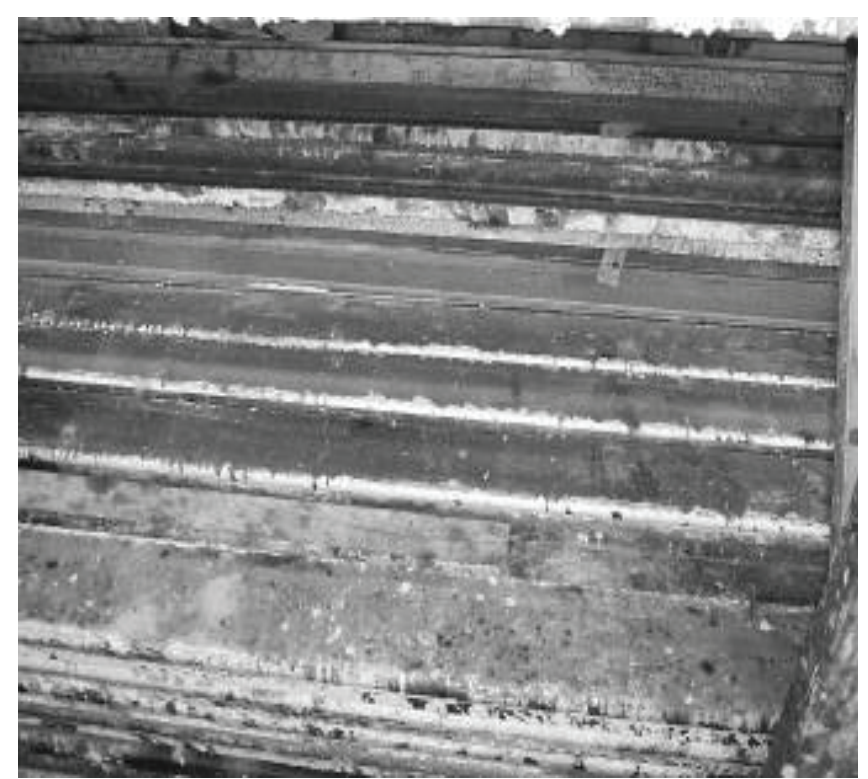

Fonte: Pesquisa de Campo (2008).

Figura 5 - Fôrmas provisórias empilhadas sob bancadas.

\subsubsection{Explorando a restrição do sistema}

Para elevar a capacidade da restrição do recurso humano da linha produtiva de forma a tirar o máximo proveito dela e garantir que o gargalo não deixe de operar, visto que qualquer minuto perdido nesse recurso é um minuto a menos no nível de produção de todo sistema, conforme advertem Goldratt e Cox (2003), é necessário deslocar outro operário de um recurso não gargalo para que esse possa auxiliar o ferreiro na máquina de corte de aço e treliça durante os períodos de maior demanda das dobras, já que estas exigem um tempo maior de operação por serem dobras que exigem medidas precisas, como pode ser observado na Figura 6, a fim de não haver perda do produto por erro de dimensões no comprimento das vigotas treliçadas.

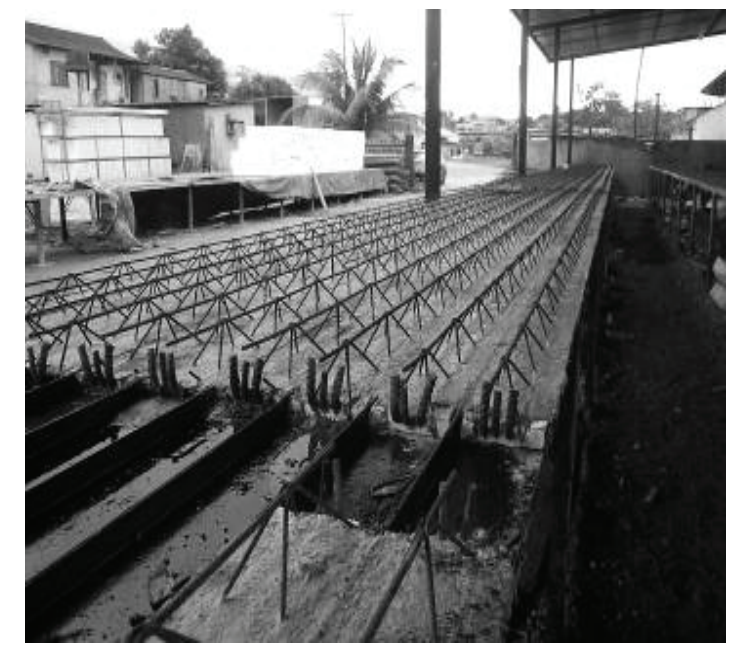

Fonte: Pesquisa de Campo (2008).

Figura 6 - Dobra dos aços.

Rev. Adm. UFSM, Santa Maria, v. 2, n. 3, p. 463-478, set./dez. 2009 
Com deslocamento de outro operário, pode-se dobrar a capacidade produtiva do ferreiro e impedir o surgimento de outro gargalo em uma etapa anterior, visto que esse deslocamento seria somente para o corte do aço que necessita das dobras naquele período da produção, e não para produção de estoque, o que poderia criar outro gargalo antes e deixar o próprio gargalo ocioso. Outra proposta é um leiaute mais eficiente, como mostra a Figura 7, onde o fluxo do processo pode ser mais bem observado por aqueles envolvidos no processo.

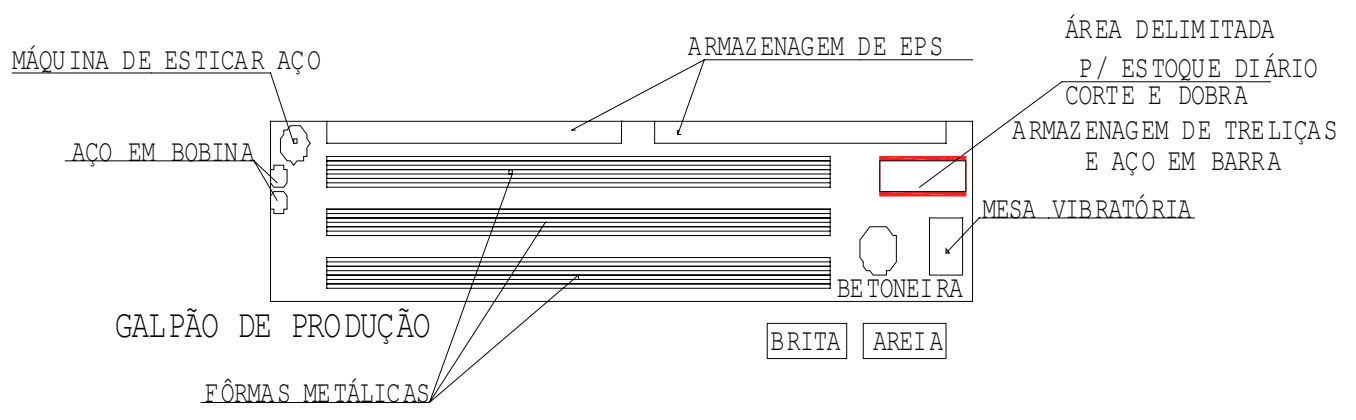

Fonte: Pesquisa de Campo (2008).

Figura 8 - Proposta para o arranjo-físico.

Para controlar a produção do ferreiro, sugeriu-se uma área de trabalho para corte e dobra fora das bancadas das vigotas. Nessa área, serão executadas as dobras do aço. No chão, ficaria demarcada outra área somente para armazenar o aço e treliças que devessem ser produzidas no dia, conforme a demanda das planilhas e a ordem de chegada.

\subsubsection{Subordinando os demais recursos}

Para análise desse próximo passo, foram subordinados todos os recursos ao gargalo. Verificou-se que a empresa estoca, atualmente, o aço e treliça para aproveitar as ofertas do mercado, com a finalidade de garantir um preço competitivo do seu produto; dessa forma, estoca material além do necessário para a produção de um mês. Entretanto, as treliças estocadas são usualmente comercializadas em Manaus, pois são utilizadas em obras residenciais e comerciais. Há outro estoque de treliças especiais (observar Figura 8), assim consideradas por terem a capacidade de vencer vãos maiores e maior capacidade de carga, que não são comumente comercializadas pela empresa.

O período em que as treliças especiais ficam esperando até serem consumidas pode chegar até 365 dias, dependendo do tipo de treliça. Observou-se que guardar essas treliças até a necessidade de seu uso não é conveniente, visto que não existe uma demanda regular para esse tipo de laje que compense o seu estoque. Outro ponto relevante é que, dependendo de como esse material fica armazenado, pode comprometer sua resistência, pois Manaus, por sua localização geográfica, é uma cidade que tem elevado índice de umidade, que agride o aço, acelerando o processo de corrosão. Além disso, a empresa não possui área para estocagem das treliças especiais e, atualmente, elas ficam dispostas sob as bancadas de produção, conforme ilustra a Figura 9.

É importante considerar que cada pedido deve ser atendido em um prazo máximo de cinco dias úteis. Sendo possível, então, programar uma compra para estoque de aço e treliça 
apenas para atender a demanda desses dias, considerando-se uma reserva de dois dias pela emissão do pedido ao fornecer e recebimento do material na fábrica. Os dias úteis trabalhados são, em média, vinte e dois por mês, no período de um turno.

A compra deve estar subordinada à capacidade produtiva do ferreiro, que é de 225 $\mathrm{kg} /$ dia entre corte e dobra de treliças e aço.

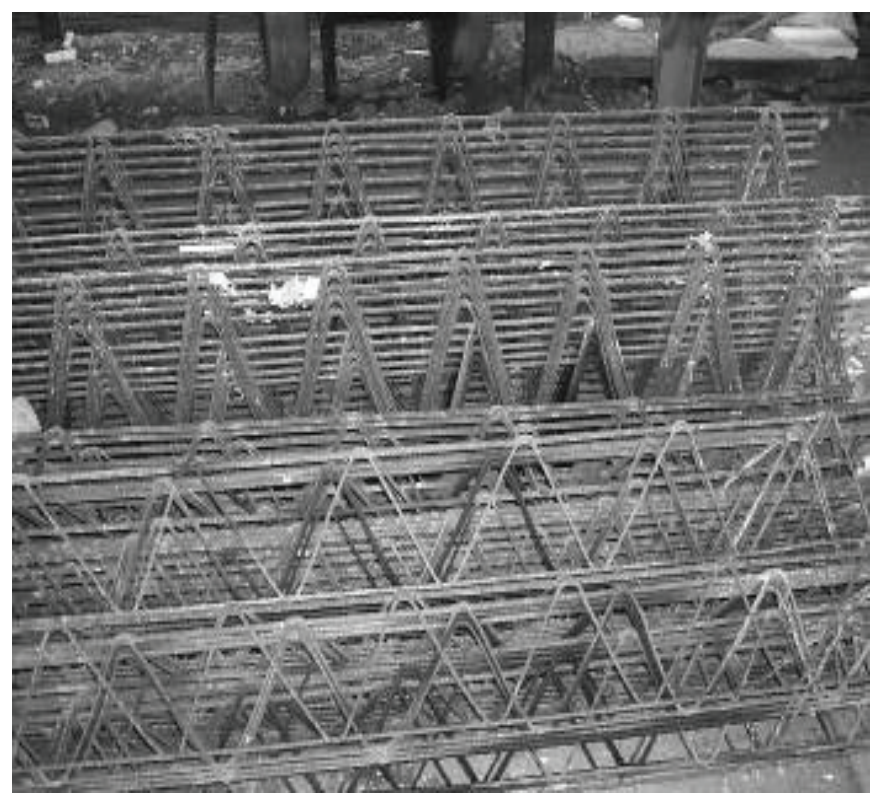

Fonte: Pesquisa de Campo (2008).

Figura 8 - Estoque de treliças especiais.

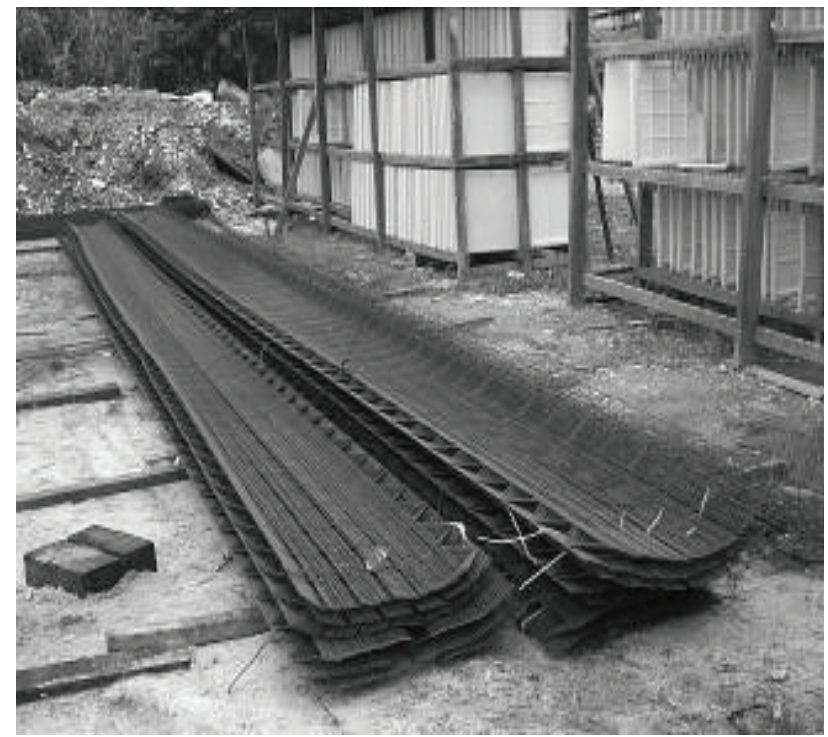

Fonte: Pesquisa de Campo (2008).

Figura 9 - Estoque de treliças usuais. 


\subsubsection{Elevando a restrição}

Mesmo com tudo que foi identificado e proposto anteriormente, ainda não foi o suficiente para aumentar a produção de aço para fabricação das vigotas treliçadas sem se utilizar das horas extras. Sua utilização pode não ser vantajosa para a empresa, primeiro porque é muito difícil conseguir a mesma produtividade pelo período noturno, em virtude da fadiga da mão de obra, o que compromete ainda mais a produção e, segundo, pelo aumento de $50 \%$ da hora normal na folha de pagamento considerando a hora extra iniciando-se das 18 até às 22 horas.

Em virtude do aço em barra de $12 \mathrm{~m}$ trabalhado em corte e dobra apresentar uma perda normal que, de acordo com o tipo de laje, pode chegar até $10 \%$, ou seja, para cada quilo trabalhado perde-se $100 \mathrm{~g}$ em média, propusemos que esse tipo de serviço seja realizado pela própria empresa que fornece o aço. As empresas que atuam no mercado de Manaus com esse tipo de serviço cobram, pelo aço cortado e dobrado, $\mathrm{R} \$ 4,04$ por quilo.

Deve-se destacar que não haverá desperdício e nem estoque desnecessário desse tipo de aço na fábrica. Outra observação relevante é manter uma parceria com os fornecedores de aço para garantir o prazo de cinco dias úteis para fabricação e entrega das lajes.

Para isso, é necessário que o pedido dos aços trabalhados junto ao fornecedor seja feito no mesmo dia do recebimento das planilhas de produção na fábrica e o material já trabalhado seja entregue em um prazo máximo de 24 horas para ser utilizado na fabricação das lajes em até 72 horas. Com isso, tem-se mais 24 horas para cura do concreto e outras 24 horas para entrega do produto, completando, assim, os cinco dias úteis, considerados como prazo ótimo pela política interna da empresa, para realizar todo processo de fabricação.

Para a fábrica comprar o aço em barras, paga-se ao fornecedor $\mathrm{R} \$ 3,86$ por quilo. Nesse caso, é necessário acrescentar ao custo o valor da mão de obra do ferreiro e do ajudante para trabalhar esse material. Considerando a tabela do Sindicato da Construção Civil no Estado do Amazonas, o salário mensal de um ferreiro é de $R \$ 668,76$ e de um ajudante é de $R \$$ 581,55 , sem incluir os encargos sociais.

Observa-se que o valor final do aço trabalhado na própria fábrica tem um custo por quilo aproximadamente $10 \%$ (dez por cento) maior em relação ao aço comprado já dobrado pelo fornecedor, sem considerar as horas extras e os encargos trabalhistas, conforme mostrado na Tabela 2.

Tabela 2 - Comparação entre o serviço executado internamente e proposta de terceirização (valores de referência Setembro/2007)

\begin{tabular}{|l|c|c|c|c|c|c|c|r|r|}
\hline & & \multicolumn{3}{|c|}{ Produção na Fábrica } & \multicolumn{3}{c|}{ Produzido pelo Fornecedor } & & \\
\hline \multicolumn{1}{|c|}{ Descricão } & Unid. & Quant. Valor R\$ & Total & Quant. & Valor R\$ & Total & Diferenca & Dif. \% \\
\hline Aço cortado e dobrado & $\mathrm{kg}$ & 8910 & 3,86 & $\mathrm{R} \$ 34.392,60$ & 8910 & 4,04 & $\mathrm{R} \$ 35.996,40$ & $\mathrm{R} \$ 1.603,80$ & $4,7 \%$ \\
\hline Mão de obra ferreiro & operário & 1 & 668,76 & $\mathrm{R} \$ 668,76$ & 0 & 0 & $\mathrm{R} \$ 0,00$ & $-\mathrm{R} \$ 668,76$ & $-100,0 \%$ \\
\hline Mão de obra ajudante & operário & 1 & 581,55 & $\mathrm{R} \$ 581,55$ & 0 & 0 & $\mathrm{R} \$ 0,00$ & $-\mathrm{R} \$ 581,55$ & $-100,0 \%$ \\
\hline Perdas de aço & $\mathrm{kg}$ & 891 & 3,86 & $\mathrm{R} \$ 3.439,26$ & 0 & 0 & $\mathrm{R} \$ 0,00$ & $-\mathrm{R} \$ 3.439,26$ & $-100,0 \%$ \\
\hline TOTAL PARCIAL & & & & $\mathrm{R} \$ 39.082,17$ & & & $\mathrm{R} \$ 35.996,40$ & $-\mathrm{R} \$ 3.085,77$ & $-7,9 \%$ \\
\hline Hora extra ferreiro & operário & 1 & 303,91 & $\mathrm{R} \$ 303,91$ & 0 & 0 & $\mathrm{R} \$ 0,00$ & $-\mathrm{R} \$ 303,91$ & $-100,0 \%$ \\
\hline Hora extra ajudante & operário & 1 & 262,6 & $\mathrm{R} \$ 262,60$ & 0 & 0 & $\mathrm{R} \$ 0,00$ & $-\mathrm{R} \$ 262,60$ & $-100,0 \%$ \\
\hline TOTAL PARCIAL & & & & $\mathrm{R} \$ 566,51$ & & & $\mathrm{R} \$ 0,00$ & $-\mathrm{R} \$ 566,51$ & $-100,0 \%$ \\
\hline TOTAL & & & & $\mathrm{R} \$ 39.648,68$ & & & $\mathrm{R} \$ 35.996,40$ & $-\mathrm{R} \$ 3.652,28$ & $-9,2 \%$ \\
\hline
\end{tabular}

Fonte: Pesquisa de Campo (2008). 


\subsubsection{Evitando a inércia no sistema}

Como, no passo anterior, a restrição foi eliminada, torna-se necessário retornar ao primeiro passo e reiniciar o ciclo, procurando a próxima restrição ao desempenho. Seguindo a lógica da melhoria contínua, esse ciclo nunca termina. Deve-se buscar continuamente a restrição e eliminá-la, não se esquecendo de que, devido à interdependência e variabilidade, cada mudança no sistema provoca novos efeitos nas restrições que foram eliminadas.

Nesse sentido, a diretoria da empresa foi conscientizada sobre a importância de continuar com o processo, inclusive estendendo o procedimento para outras áreas da empresa (atendimento ao cliente, pré-venda, pós-venda, marketing etc.).

Por conta das melhorias propostas na produção (tanto operacional, quanto financeira), os diretores demonstraram-se inclinados a continuar com o processo de melhoria, conforme sugerido, realizando reuniões mensais para renovar o ciclo de análise dos cinco passos propostos pela TOC. Assim, garante-se que melhorias contínuas estejam sempre sendo realizadas, impedindo que a inércia tome conta do sistema e acabe se tornando a própria restrição (GOLDRATT, 1992).

\subsection{Resultados obtidos}

A implantação da TOC na empresa foi entendida como positiva pela diretoria. Isto ocorreu, principalmente, devido ao potencial aumento na produção e porque todos os envolvidos estavam cientes dessa necessidade. Inicialmente observaram-se algumas resistências, principalmente relacionadas à eliminação de estoques de matéria-prima. Porém, uma vez explicado o método e fazendo-se com que os diretores estudassem o assunto e expusessem suas ideias sobre o modo implantação da TOC na empresa, as resistências foram vencidas.

No decorrer do trabalho, verificou-se a possibilidade de a empresa aumentar sua produção sem aumentar seus custos fixos nem seu quadro de funcionários. Este aumento referese ao aumento das horas disponíveis pela eliminação da restrição inicial, a saber, o trabalho manual de corte e dobra da matéria-prima pelo ferreiro e seu ajudante.

Após a aplicação da metodologia proposta, a empresa encaminha-se para a obtenção de um melhor detalhamento de todo o seu processo produtivo. No entanto, por ser uma empresa de pequeno porte e recém-instalada, ainda não possui softwares sofisticados para um melhor gerenciamento do sistema e para facilitar a administração de todos esses dados, podendo beneficiar-se ainda mais. O sequenciamento da produção ainda está sendo feito manualmente.

De acordo com o estudo, pode-se verificar a possibilidade de programar melhor a compra de aço cortado e dobrado para as lajes que têm um maior consumo desse material, particularmente o que é vendido em varas de 12 metros e que representa a maior parcela da perda quando trabalhados na própria fábrica.

Com base na análise efetuada, os dados indicam que a empresa poderá reduzir seus custos de produção e operações em até 9,2\% no que diz respeito à produção de seu principal produto, as lajes pré-fabricadas.

A TOC, para a empresa analisada, mostrou-se perfeitamente aplicável. A restrição do sistema foi identificada pelo método do cálculo da carga no recurso, o que foi, posteriormente, confirmado com experimentação prática na rotina da organização. Explorou-se o gargalo com o intuito de aumentar o ganho da empresa. Os recursos não-gargalo foram subordinados ao 
recurso crítico, trabalhando no mesmo ritmo, o que apontou para uma redução dos estoques em processo, pela compra programada com base na capacidade do recurso crítico.

Com as melhorias propostas pela implantação da TOC, a empresa pode analisar a possibilidade de reduzir seu quadro de pessoal de forma mais segura, sem comprometer a produção. Cabe destacar que, a priori, a TOC não faz apologia da demissão de funcionários como meio para redução de despesas operacionais. Em linhas gerais, a teoria das restrições advoga uma melhor alocação dos recursos, inclusive funcionários, em áreas onde possam contribuir mais com os resultados da empresa.

A TOC mostrou-se eficaz na empresa analisada, permitindo uma redução nos estoques em processo em função da criação do Pulmão entre a restrição e os outros processos, puxando a produção. O método também permitiu a visualização dos problemas que estavam escondidos pelos altos estoques como: falhas de qualidade que antes levariam mais tempo para serem detectadas, recursos financeiros mal alocados, degradação de matérias-primas, em especial do aço.

\section{Conclusão}

Este artigo mostrou o estudo da otimização do processo de fabricação de treliças para construção civil. Na pesquisa, procurou-se inicialmente identificar os gargalos que estavam impedindo o atendimento da demanda da empresa. Depois foram avaliadas as soluções para que a fábrica aumentasse a eficiência da restrição no sistema. Seguindo todos os passos propostos por essa metodologia, chegou-se à evidência de que o recurso gargalo era um grande gerador de despesas operacionais e que, por isso, estava impedindo o aumento da produção como um todo.

Concluiu-se que, por se tratar de uma fábrica que existe há menos de um ano no mercado e ainda instalada de forma provisória, é necessário que se implantem logo medidas de exploração da restrição, com a finalidade de reduzir o desperdício. A reorganização do leiaute de forma mais eficiente certamente trará benefícios substanciais.

O maior benefício com a implantação das novas medidas será o valor final do produto e os ganhos financeiros com a redução das perdas. Para manter o processo de melhoria, é necessário também que o sistema seja revisto semanalmente, a fim de que o mesmo não entre em inércia. Dessa forma, é importante o envolvimento da diretoria no sentido de investir no treinamento dos funcionários para que estes possam apontar os gargalos antes que afetem demasiadamente a produção e o atendimento dos pedidos.

O trabalho inicial levantou uma série de possibilidades de futuras investigações. Como possibilidade de futura pesquisa, a implantação das melhorias propostas é uma oportunidade de se constatar os fatores de estímulo e os que limitam o processo de melhoria com a TOC. A concretização de novos ciclos de melhoria baseados na Teoria das Restrições no mesmo ambiente deste estudo permitirá que se observe se os ganhos com a eliminação das restrições são realmente sustentáveis no tempo.

Fica evidente o potencial de melhoria de processos que a Teoria das Restrições traz para a organização. Dessa forma, a extrapolação da TOC para outros departamentos da empresa é uma possibilidade interessante que poderia ser abordada, uma vez que os resultados propostos nesta etapa da pesquisa sejam postos em prática. Outra questão que pode ser explorada em maior profundidade é a de que a implantação da TOC trará melhorias além das observáveis no aspecto financeiro e da produtividade fabril. 


\section{Referências}

AGUIAR, R. F., SILVA, L. T., CAULLIRAUX, H.M., PRADO, C.A.S. A Teoria das Restrições em um processo produtivo de fabricação de chapas de gesso acartonado no Brasil. In: ENCONTRO NAC. DE ENG. DE PRODUÇÃO, 24., 2004, Florianópolis. Anais... São Paulo: Abepro, 2004. p.141-148.

BOTELHO, M. H. C.; MARCHETTI, O. Concreto armado, eu te amo. 3. ed. São Paulo: Edgard Blücher, 2002.

COX III, J. F; SPENCER, M. S. Manual da Teoria das Restrições. Porto Alegre: Bookman, 2002.

CORRÊA, H. L.; GIANESI, I. G. N. Just in time, MRP II e OPT: um enfoque estratégico. 2. ed. São Paulo: Atlas, 1996.

GOLDRATT, E. M.; COX, J. A meta: um processo de melhoria contínua. 2. ed. São Paulo: Nobel, 2003.

GOLDRATT, E. M. A síndrome do palheiro: garimpando informações em um oceano de dados. São Paulo: Educator, 1992.

GUERREIRO, R. A meta da empresa, seu alcance sem mistérios. 2. ed. São Paulo: Atlas, 1999.

MARTINS, F. A. O processo de raciocínio da teoria das restrições na indústria moveleira de pequeno porte: um estudo de caso. 2002. 105f. Dissertação (Mestrado em Engenharia de Produção) - Programa de Pós-Graduação em Engenharia de Produção, Universidade Federal de Santa Catarina, Florianópolis, 2002.

NOREEN, E.; SMITH, D.; MACKEY, J.T. A Teoria das Restrições e suas implicações na contabilidade gerencial. São Paulo: Educator, 1996.

PROCÓPIO, M.; SILVA, A. M. Estudo de caso: compreender descrevendo. Lisboa: DEFCUL, 2005.
QUEIROZ, J. A. de. Proposta de um método de gestão econômica para os sistemas produtivos tendo como base teórica os pressupostos que sustentam a contabilidade de ganhos da teoria das restrições e os princípios da produção enxuta. 2006. 159f. Tese (Doutorado em Engenharia de Produção) - Escola de Engenharia de São Carlos, Universidade de São Paulo, São Carlos, 2006.

RESENDE JÚNIOR, P. C. Abordagem do gerenciamento de processos finalísticos em sistemas logísticos do setor de serviços: aplicação da teoria das restrições. 2006. 114f. Dissertação (Mestrado em Administração) Universidade de Brasília, Brasília, 2006.

SOUZA, A. A. C. de. Aplicação da metodologia Tambor-Pulmão-Corda (TPC) com supermercado na gestão de manufatura de eletrodos de grafite das candeias e Monterrey da Grafitech International Ltda. 2006.

112f. Dissertação (Mestrado Profissional em Administração) - Núcleo de Pós-Graduação em Administração, Universidade Federal da Bahia, Salvador, 2006.

VERGARA, S. C. Projetos e relatórios de pesquisa em administração. 5. ed. São Paulo: Atlas, 2004.

YIN, R.K. Estudo de caso: planejamento e métodos. 3. ed. São Paulo: Bookman, 2004. 